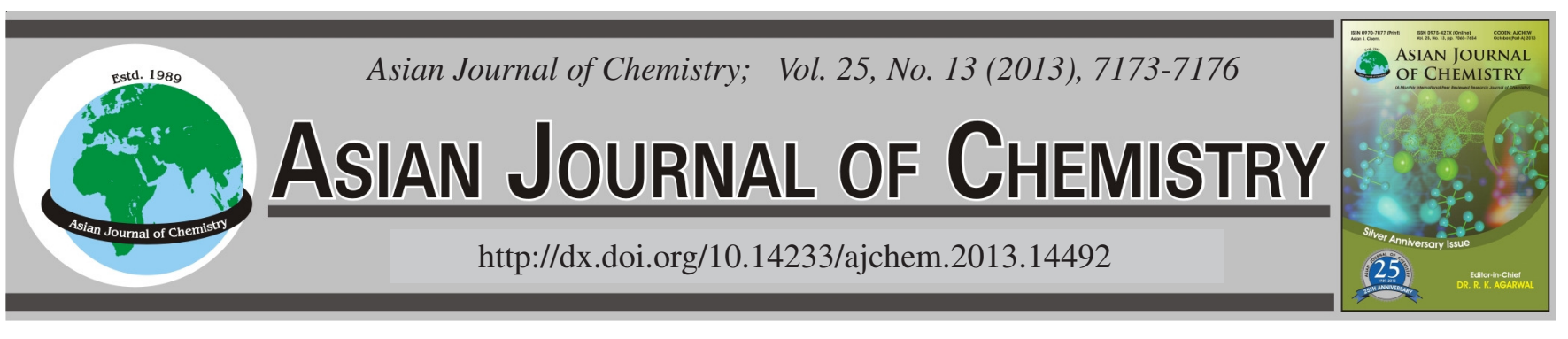

\title{
Chemical Constituents, Antimicrobial Activity, Antioxidant and Total Phenolic Content Within the leaves of Thecocarpus meifolious Boiss., Umbelliferae Herbs Growing Wild in Iran
}

\author{
Mahboube TAherkhani ${ }^{*}$ and Abdolhossein Rustaiyan
}

Department of Chemistry, Science and Research Branch, Islamic Azad University, Tehran, Iran

*Corresponding author: Tel: +98 912 5039918; E-mail: mahtaherkhani@yahoo.com

Water-distilled essential oil from the leaves of Thecocarpus meifolious Boiss. which is endemic to Iran, collected from the province of Chaharmahal-Bakhtiyari, west of Iran, was analyzed by GC and GC-MS. The leaf oil of T. meifolious investigated to analyze their antimicrobial activity, antioxidant and total phenolic content. Antioxidative properties of this oil was determined by 3 methods i.e., by ferric-reducing antioxidant power (FRAP), radical-scavenging capacity of the oil or bleaching of 2,20-diphenylpicrylhydrazyl (DPPH) and $\beta$-carotene-linoleic acid assay. Spathulenol (20.51\%), camphor $(10.20 \%)$ and caryophyllene oxide $(10.35 \%)$ were the major components in this oil. This oil indicated significant activity Candida albicans and moderate inhibitory activity against the gram-negative bacteria. The results suggest application of T. meifolious oil as a natural antioxidant agent.

Key Words: Thecocarpus meifolious, Essential oil, Spathulenol, Antimicrobial, Antioxidant, Total phenolic content.

ᄂ - - - - - - - - - - - - - - - - - - - - - - - - - - - -

\section{INTRODUCTION}

The genus Thecocarpus, is represented in the flora of Iran by only one species, T. meifolious Boiss. This plant growing wild in Isfahan, Fars, Chaharmahal-Bakhtiarie and KohkiloyeBoyerahmad Provinces of $\operatorname{Iran}^{1,2}$. No studies on the biological activities of the oil of Thecocarpus species have previously been reported. In previous investigation, 40 compounds were identified in the aerial part oil of Thecocarpus meifolious representing $90.2 \%$ of the total oil with spathulenol (30.8\%) and caryophyllene oxide $(11.1 \%)$ as the major constituents ${ }^{3}$. The present study deals with the chemical composition, antibacterial, antioxidative and radical-scavenging properties of the leaf essential oil of T. meifolious obtained by steamdistillation.

\section{EXPERIMENTAL}

The aerial parts of T. meifolious, which is endemic to Iran, were collected from Shahrekord, Province of ChaharmahalBakhtiyari, west of Iran, in July 2011. Voucher specimens have been deposited at the Herbarium of the Research Institute of Forests and Rangelands (TARI), Tehran, Iran.

Isolation of the essential oil: The leaves of T. meifolious were dried at room temperature for several days. Air-dried leaves of T. meifolious ( $80 \mathrm{~g}$ ) was separately subjected to hydrodistillation using a Clevenger-type apparatus for $3 \mathrm{~h}$.
After decanting and drying of the oil over anhydrous sodium sulphate, the oil was recovered. Results showed that essential oil yield was $0.6 \%$ (w/w).

Analysis of the the essential oil: The composition of the essential oil obtained by hydrodistillation from the leaves of T. meifolious was analyzed by GC and GC/MS. Identification of the constituents of oil was achieved by comparison of their mass spectra and retention indices with those reported in the literature and those of authentic samples ${ }^{4}$.

Gas chromatography: GC analysis was performed on a Schimadzu 15A gas chromatography equipped with a split/ splitless injector $\left(250{ }^{\circ} \mathrm{C}\right)$ and a flame ionization detector $\left(250^{\circ} \mathrm{C}\right)$. Nitrogen was used as carrier gas $(1 \mathrm{~mL} / \mathrm{min})$ and the capillary column used was DB-5 $(50 \mathrm{~m} \times 0.2 \mathrm{~mm}$, film thickness $0.32 \mu \mathrm{m})$. The column temperature was kept at $60^{\circ} \mathrm{C}$ for $3 \mathrm{~min}$ and then heated to $220^{\circ} \mathrm{C}$ with a $5{ }^{\circ} \mathrm{C} / \mathrm{min}$ rate and kept constant at $220^{\circ} \mathrm{C}$ for $5 \mathrm{~min}$. Relative percentage amounts were calculated from peak area using a Schimadzu C-R4A chromatopac without the use of correction factors.

Gas chromatography-mass spectroscopy: GC-MS analysis was performed using a Hewlett-Packard 5973 with a HP-5MS column $(30 \mathrm{~m} \times 0.25 \mathrm{~mm}$, film thickness $0.25 \mu \mathrm{m})$. The column temperature was kept at $60{ }^{\circ} \mathrm{C}$ for $3 \mathrm{~min}$ and programmed to $220^{\circ} \mathrm{C}$ at a rate of $5^{\circ} \mathrm{C} / \mathrm{min}$ and kept constant at $220^{\circ} \mathrm{C} / \mathrm{min}$ for $5 \mathrm{~min}$. The flow rate of helium as carrier gas (1 $\mathrm{mL} / \mathrm{min})$. MS were taken at $70 \mathrm{eV}$. The retention indices 
for all the components were determined according to the Van Den Dool method, using $n$-alkanes as standards. The compounds were identified by (RRI, DB5) with those reported in the literature and by comparison of their mass spectra with the Wiley library or with the published mass spectra ${ }^{4}$.

Oil dilution solvent: Bacterial strains were streaked on Mueller Hinton agar plates using sterile cotton swabs. Five microlitres of dimethyl sulphoxide, loaded on sterile blank disks, were placed on the agar plates and were incubated at $37^{\circ} \mathrm{C}$ for $24 \mathrm{~h}$. There was no antibacterial activity on the plates and hence DMSO was selected as a safe diluting agent for the oil. Five microlitres from each oil dilution, followed by sterilization, using a $0.45 \mu \mathrm{m}$ membrane filter, were added to sterile blank discs. The solvent also served as control.

Microbial strain and growth media: Pseudomonas aeruginosa (ATCC8830), Escherichia coli (ATCC25922), Staphylococcus aureus (ATCC25923), Candida albicans (ATCC 5027) and Acinetobacter baumannii (ATCC 17978) were employed in the study. Nutrient agar was used. Bacterial suspensions were made in brain heart infusion (BHI) broth to a concentration of $c a .10^{8} \mathrm{cfu} / \mathrm{mL}$. Subsequent dilutions were made from the above suspension, which were then used in the tests.

Oil sterility test: In order to ensure sterility of the oils, geometric dilutions, ranging from 0.036 to $72 \mathrm{mg} / \mathrm{mL}$ of the essential oil, were prepared in a 96-well microtitre plate, including one growth control (BHI + Tween 80$)$ and one sterility control (BHI + Tween $80+$ test oil). Plates were incubated under normal atmospheric conditions, at $37^{\circ} \mathrm{C}$ for $24 \mathrm{~h}$. The contaminating bacterial growth, if at all, was indicated by the presence of a white "pellet" on the well bottom.

Disc diffusion method: The agar disc diffusion method was employed for the determination of antimicrobial activities of the essential oils. Briefly, $0.1 \mathrm{~mL}$ from $10^{8} \mathrm{cfu} / \mathrm{mL}$ bacterial suspension was spread on the Mueller Hinton Agar (MHA) plates. Filter paper discs ( $6 \mathrm{~mm}$ in diameter) were impregnated with $5 \mu \mathrm{L}$ of the undiluted oil and were placed on the inoculated plates. These plates, after remaining at $4{ }^{\circ} \mathrm{C}$ for $2 \mathrm{~h}$, were incubated at $37^{\circ} \mathrm{C}$ for $24 \mathrm{~h}$. The diameters of the inhibition zones were measured in millimeters. All tests were performed in triplicate.

Determination of minimum inhibitory (MIC) and bactericidal (MBC) concentrations: All tests were performed in brain heart infusion (BHI) broth supplemented with Tween 80 detergent (final concentration of $0.5 \%(\mathrm{v} / \mathrm{v})$. Test strains were suspended in BHI broth to give a final density of $10^{7} \mathrm{cfu} /$ $\mathrm{mL}$ and these were confirmed by viable counts. The minimal inhibitory concentration (MIC) and minimal bactericidal concentration (MBC) were assessed according to our modified procedure ${ }^{5}$. MIC was determined by a broth dilution method in test tubes as follows: $40 \mu \mathrm{L}$ from each of various dilutions of the oils were added to $5 \mathrm{~mL}$ of brain heart infusion (BHI) both in tubes containing $10^{7} \mathrm{cfu} / \mathrm{mL}$ of live bacterial cells. The tubes were then incubated on an incubator shaker to evenly disperse the oil throughout the broth in tubes. The highest dilution (lowest concentration), showing no visible growth, was regarded as the MIC. Cell suspensions $(0.1 \mathrm{~mL})$ from the tubes showing no growth were subcultured on BHI agar plates in triplicate to determine if the inhibition was reversible or permanent. MBC was determined as the highest dilution (lowest concentration) at which no growth occurred on the plates.

Bactericidal kinetics of the oil: Forty microlitres of each oil at the dilution determined by MBC, was added to each $5 \mathrm{~mL}$ of brain heart infusion (BHI) broth in tubes containing bacterial suspension of $10^{7} \mathrm{cfu} / \mathrm{mL}$ and were then incubated at $37^{\circ} \mathrm{C}$ in an incubator shaker. Samples $(0.1 \mathrm{~mL})$ were taken after 5, 10, 15, 20, 25, 30, 45, 90, 120, 150, 180, 210 and 240 min. The samples were immediately washed with sterile phosphate buffer, $\mathrm{pH} 7.0$, centrifuged at $10000 \mathrm{rpm}$ for $1 \mathrm{~min}$, resuspended in the buffer and were then spread-cultured on BHI agar for $24 \mathrm{~h}$ at $37^{\circ} \mathrm{C}$. Phosphate buffer was used as diluent when needed. Bactericidal experiments were performed three times. Microbial colonies were counted from triplicates after the incubation period and the mean total number of viable cells per $\mathrm{mL}$ was calculated. The mean total number of viable bacteria from bactericidal kinetics experiments at each time interval was converted to $\log _{10}$ viable cells using routine mathematical formulae. The trend of bacterial death was plotted graphically.

Ferric-reducing antioxidant power (FRAP) assay of the oil: The FRAP assay was carried out according to the procedure employed by Lim et al. ${ }^{6}$. One millilitre of the extract dilution was added to $2.5 \mathrm{~mL}$ of $0.2 \mathrm{M}$ potassium phosphate buffer (pH 6.6) and $2.5 \mathrm{~mL} 1 \%$ potassium ferricyanide. The mixture was incubated for $20 \mathrm{~min}$ at $50^{\circ} \mathrm{C}$, after which $2.5 \mathrm{~mL}$ of $10 \%$ trichloroacetic acid was added. The mixture was then separated into aliquots of $2.5 \mathrm{~mL}$ and mixed with $2.5 \mathrm{~mL}$ of deionised water. Then, $0.5 \mathrm{~mL}$ of $0.1 \%$ (w/v) $\mathrm{FeCl}_{3}$ were added to each tube and allowed to stand for $0.5 \mathrm{~h}$. Absorbance for each tube was measured at $700 \mathrm{~nm}$. The FRAP was expressed as gallic acid equivalents (GAE) in $\mathrm{mg} / \mathrm{g}$ of samples used.

Radical-scavenging capacity of the oil: The hydrogen atom or electron donation abilities of the corresponding extracts and some pure compounds were measured from the bleaching of the purple-coloured methanol solution of 2,2diphenylpicrylhydrazyl (DPPH). This spectrophotometric assay uses the stable radical DPPH as a reagent ${ }^{7,8}$. Fifty microlitres of 1:5 concentrations of the essential oils in methanol were added to $5 \mathrm{~mL}$ of a $0.004 \%$ methanol solution of DPPH. Trolox (1 mM) (Sigma-Aldrich), a stable antioxidant, was used as a synthetic reference. The essential oil from Thymus Xporlock was used as a natural reference. After a $0.5 \mathrm{~h}$ incubation period at room temperature, the absorbance was read against a blank at $517 \mathrm{~nm}$. Inhibition of free radical by DPPH (I \%) was calculated in following way:

$$
\mathrm{I} \%=\left(\frac{\mathrm{A}_{\text {Blank }}-\mathrm{A}_{\text {Sample }}}{\mathrm{A}_{\text {Blank }}}\right) \times 100
$$

where $A_{B l a n k}$ is the absorbance of the control reaction (containing all reagents except the test compound) and $\mathrm{A}_{\text {Sample }}$ is the absorbance of the test compound. Tests were carried out in triplicate.

$\boldsymbol{\beta}$-Carotene-linoleic acid assay: Antioxidant activity of essential oils was determined using the $\beta$-carotene bleaching test $^{9}$. Ca. $10 \mathrm{mg}$ of $\beta$-carotene (type I synthetic, Sigma-Aldrich) was dissolved in $10 \mathrm{~mL}$ of chloroform. The carotene-chloro- 
form solution, $0.2 \mathrm{~mL}$, was pipetted into a boiling flask containing $20 \mathrm{mg}$ linoleic acid (Sigma-Aldrich) and $200 \mathrm{mg}$ Tween 40 (Sigma-Aldrich). Chloroform was removed using a rotary evaporator at $40{ }^{\circ} \mathrm{C}$ for $5 \mathrm{~min}$ and, to the residue, $50 \mathrm{~mL}$ of distilled water were added, slowly with vigorous agitation, to form an emulsion. Five millilitres of the emulsion were added to a tube containing $0.2 \mathrm{~mL}$ of essential oil solution, prepare ${ }^{10}$ and the absorbance was immediately measured at $470 \mathrm{~nm}$ against a blank, consisting of an emulsion without $\beta$-carotene. The tubes were placed in a water bath at $50^{\circ} \mathrm{C}$ and the oxidation of the emulsion was monitored spectrophotometrically by measuring absorbance at $470 \mathrm{~nm}$ over a $1 \mathrm{~h}$ period. Control samples contained $10 \mu \mathrm{L}$ of water instead of essential oils. Butylated hydroxy anisole (BHA; Sigma-Aldrich), a stable antioxidant, was used as a synthetic reference. The antioxidant activity was expressed as inhibition percentage with reference to the control after $1 \mathrm{~h}$ of incubation, using the following equation:

$$
\mathrm{AA}=\frac{100\left(\mathrm{DR}_{\mathrm{C}}-\mathrm{DRS}_{\mathrm{S}}\right)}{\mathrm{DR}_{\mathrm{C}}}
$$

where $\mathrm{AA}=$ antioxidant activity, $\mathrm{DR}_{\mathrm{C}}=$ degradation rate of the control $=[\ln (\mathrm{a} / \mathrm{b}) / 60], \mathrm{DRS}=$ degradation rate in presence of the sample $=[\ln (\mathrm{a} / \mathrm{b}) / 60], \mathrm{a}=$ absorbance at time $0, \mathrm{~b}=$ absorbance at $1 \mathrm{~h}$.

Total phenolic content assay: Total phenol content was estimated as gallic acid equivalents (GAE; mg gallic acid/g extract). In brief, a $100 \mu \mathrm{L}$ aliquot of dissolved extract was transferred to a volumetric flask, containing $46 \mathrm{~mL}$ distilled $\mathrm{H}_{2} \mathrm{O}$, to which was subsequently added $1 \mathrm{~mL}$ Folin-Ciocalteu reagent. After $3 \mathrm{~min}, 3 \mathrm{~mL}$ of $2 \% \mathrm{Na}_{2} \mathrm{CO}_{3}$ was added. After $2 \mathrm{~h}$ of incubation at $25^{\circ} \mathrm{C}$, the absorbance was measured at $760 \mathrm{~nm}$. Gallic acid (Sigma Co., 0.2-1.0 mg/mL gallic acid) was used as the standard for the calibration curve and the total phenolic contents were expressed as mg gallic acid equivalents per gram of tested extracts.

\section{RESULTS AND DISCUSSION}

Chemical composition of the essential oil: The composition of the essential oil obtained by hydrodistillation from the leaves of T. meifolious, from Iran, was analyzed by GC and GC/MS (Table-1). The percentage and retention indices of components are given. In the leaf oil of T. meifolious, 30 components, representing $97.53 \%$ of the total composition were identified. Spathulenol (20.51\%), camphor $(10.20 \%)$ and caryophyllene oxide $(10.35 \%)$ were the major components in this oil. The other main components of leaf oil of $T$. meifolious were germacrene D $(8.68 \%), \beta$-caryophyllene $(5.75 \%)$ and $\beta$-elemene $(5.17 \%)$. The leaf oil of T. meifolious consists of 2 monoterpene hydrocarbons $(2.07 \%), 3$ oxygentated monoterpene $(14.82 \%), 13$ sesquiterpene hydrocarbons $(31.9 \%), 9$ oxygentated sesquiterpenes $(46.35 \%)$ and 3 non terpenoid compounds $(2.39 \%)$. As can be seen from the above information, the leaf oil of $T$. meifolious are rich in sesquiterpenes $(78.25 \%)$. As shown in Table-1, the largest part of the leaf oil of T. meifolious essential oil was formed by oxygenated sesquiterpenes (46.35\%). In previous study, 40 compounds were identified in the aerial part oil of $T$. meifolious
TABLE-1

COMPOSITION OF THE LEAF OIL OF T. meifolious BOISS

\begin{tabular}{|c|c|c|}
\hline Compound & $\mathrm{RI}^{*}$ & Percentage $(\%)$ \\
\hline Heptanal & 900 & 0.49 \\
\hline$\alpha$-Pinene & 939 & 1.45 \\
\hline Octanal & 1001 & 1.20 \\
\hline Limonene & 1031 & 0.62 \\
\hline Linalool & 1098 & 3.8 \\
\hline Camphor & 1143 & 10.20 \\
\hline 1-Methyl naphtalene & 1291 & 0.7 \\
\hline$\delta$-Elemene & 1339 & 0.87 \\
\hline Pinocarvone & 1162 & 0.82 \\
\hline$\alpha$-Copaene & 1376 & 0.9 \\
\hline$\beta$-Bourbonene & 1384 & 0.8 \\
\hline$\beta$-Elemene & 1391 & 5.17 \\
\hline$\beta$-Caryophyllene & 1418 & 5.75 \\
\hline$\beta$-Gurjunene & 1432 & 0.51 \\
\hline$\alpha$-Humulene & 1454 & 1.25 \\
\hline (E)- $\beta$-Farnesene & 1458 & 0.86 \\
\hline$\gamma$-Muurolene & 1477 & 1.90 \\
\hline Germacrene D & 1480 & 8.68 \\
\hline$\beta$-Selinene & 1458 & 0.52 \\
\hline Bicyclogermacrene & 1494 & 2.89 \\
\hline$\delta$-Cadinene & 1524 & 1.8 \\
\hline Spathulenol & 1576 & 20.51 \\
\hline Caryophyllene oxide & 1581 & 10.35 \\
\hline$\beta$-Copaen-4- $\beta$-ol & 1584 & 1.57 \\
\hline Humulene epoxide II & 1606 & 1.89 \\
\hline trans-Iso longifolanone & 1618 & 1.6 \\
\hline Isospathulenol & 1636 & 3.45 \\
\hline Cedr-8-(15)-en-9- $\alpha$-ol & 1644 & 2.78 \\
\hline$\alpha$-Muurolol & 1645 & 2.43 \\
\hline 14-Hydroxy- $\alpha$-muurolene & 1775 & 1.77 \\
\hline Monoterpene hydrocarbons & & 2.07 \\
\hline Oxygenated monoterpenes & & 14.82 \\
\hline Sesquiterpene hydrocarbons & & 31.9 \\
\hline Oxygenated sesquiterpenes & & 46.35 \\
\hline Others & & 2.39 \\
\hline Total & & 97.53 \\
\hline
\end{tabular}

RI, Retention indices were as determined on a DB-5 column using the homologous series of $n$-alkanes.

representing $90.2 \%$ of the total oil with spathulenol (30.8\%) and caryophyllene oxide $(11.1 \%)$ as the major constituents. In other words, the oil of T. meifolious consists of two monoterpene hydrocarbons $(0.7 \%)$, one oxygentated monoterpene $(0.7 \%), 13$ sesquiterpene hydrocarbons (24.8\%), 15 oxygentated sesquiterpenes $(58.9 \%)$ and 9 non terpenoid compounds $(11.1 \%)$. Spathulenol $(30.8 \%)$ and caryophyllene oxide $(11.1 \%)$ were the major compounds in the oil, followed by germacrene $\mathrm{D}(7.0 \%)$ and octanal $(5.5 \%)^{3}$. As can be seen from the above information, the essential oil from the leaves and total aerial parts of $T$. meifolious are rich in sesquiterpenes (78.25 and $83.7 \%$ ), respectively.

Antibacterial activity: The antibacterial activities of $T$. meifolious oil was assayed against and results presented in Table-2. The antibacterial activities of the essential oils were evaluated by disc diffusion method using Muller-Hinton Agar for bacteria with determination of inhibition zones (IZ), minimal inhibitory concentration (MIC), minimum bactericidal concentration $(\mathrm{MBC})$ and decimal reduction time (D-value). 


\begin{tabular}{|c|c|c|c|c|}
\hline \multicolumn{5}{|c|}{$\begin{array}{c}\text { TABLE-2 } \\
\text { ANTIMICROBIAL ACTIVITIES OF THE } \\
\text { LEAF OIL OF Thecocarpus meifolious }\end{array}$} \\
\hline \multirow[b]{2}{*}{ Microorganisms } & \multicolumn{3}{|c|}{ T. meifolious } & \multirow{2}{*}{$\begin{array}{l}\text { D } \\
\text { Value } \\
\text { (min) }\end{array}$} \\
\hline & $\begin{array}{c}\mathrm{IZ} \\
(\mathrm{mm})\end{array}$ & $\begin{array}{c}\mathrm{MIC} \\
(\mathrm{mg} / \mathrm{mL})\end{array}$ & $\begin{array}{c}\mathrm{MBC} \\
(\mathrm{mg} / \mathrm{mL})\end{array}$ & \\
\hline $\begin{array}{l}\text { Pseudomonas aeruginosa } \\
\text { ATCC } 8830\end{array}$ & 14 & 5 & 10 & 19.14 \\
\hline $\begin{array}{l}\text { Escherichia coli } \\
\text { ATCC25922 }\end{array}$ & 35 & 1 & 2.5 & 7.87 \\
\hline $\begin{array}{l}\text { Staphylococcus aureus } \\
\text { ATCC } 25923\end{array}$ & 21 & 2.5 & 5 & 16.52 \\
\hline $\begin{array}{l}\text { Candida albicans } \\
\text { ATCC } 5027\end{array}$ & 58 & 0.5 & 1 & 5.64 \\
\hline $\begin{array}{l}\text { Acinetobacter baumannii } \\
\text { TCC } 17978\end{array}$ & 20 & 2.5 & 5 & 16.55 \\
\hline
\end{tabular}

The present study revealed the leaf essential oil of $T$. meifolious indicated significant activity against Candida albicans and moderate inhibitory activity against the gramnegative bacteria especially Escherichia coli.

Bactericidal kinetics of the oils: Table- 2 show reduction times of $P$. aeruginosa, E. coli, S. aureus, C. albicans and A. baumannii, respectively, after exposure to the MBC levels of the oils. It can be concluded that $C$. albicans is the most vulnerable to the oil under study. These values suggest the duration of time required for complete bactericidal effects of the oils.

Total phenol contents: As shown in Table-3, the total phenol contents (TPC) of the leaf oil of T. meifolious was determined to be $126.80 \pm 8.50 \mu \mathrm{g}$ gallic acid equivalent/mg sample (GAE/mg).

\begin{tabular}{|c|c|}
\hline \multicolumn{2}{|c|}{$\begin{array}{c}\text { TABLE-3 } \\
\text { ANTIOXIDANT ACTIVITY AND TOTAL PHENOLICS } \\
\text { OF LEAF ESSENTIAL OIL OF T. meifolious }\end{array}$} \\
\hline DPPH effect (\%) (amount of essential oil) & $\begin{array}{c}55.6 \pm 1.5(10 \\
\mathrm{mg} / \mathrm{mL})\end{array}$ \\
\hline $\operatorname{DPPH}\left(\mathrm{IC}_{50}\right)(\mu \mathrm{g} / \mathrm{mL})$ & 3.75 \\
\hline $\begin{array}{l}\beta \text {-Carotene-linoleic acid assay (amount of } \\
\text { essential oil) }\end{array}$ & $\begin{array}{c}40.65 \pm 2.5 \\
(0.625 \mathrm{mg} / \mathrm{mL})\end{array}$ \\
\hline $\begin{array}{l}\text { Ferric-reducing antioxidant power (FRAP) (gallic } \\
\text { acid equivalent }(\mathrm{mg} / \mathrm{g})\end{array}$ & $8.55 \pm 0.5$ \\
\hline $\begin{array}{l}\text { Total phenolic content GAE ( } \mu \text { g gallic acid/mg } \\
\text { sample) }\end{array}$ & $126.80 \pm 8.50$ \\
\hline
\end{tabular}

Antioxidant activity: Antioxidative properties of the leaves essential oil of T. meifolious was determined by 3 methods i.e., ferric-reducing antioxidant power (FRAP), radical-scavenging capacity of the oil or bleaching of 2,20- diphenylpicrylhydrazyl (DPPH) and $\beta$-carotene-linoleic acid assay. The results suggest application of T. meifolious oil as a natural antioxidant agent.

Ferric-reducing antioxidant power (FRAP) assay of the oil: The FRAP assay was expressed as gallic acid equivalents (GAE) in $\mathrm{mg} / \mathrm{g}$ of samples used. The ferric reducing power of the essential oils was determined $8.55 \pm 0.5$ gallic acid equivalent $(\mathrm{mg} / \mathrm{g})$.

Free radical-scavenging capacities of the oils: The DPPH radical-scavenging activities of the essential oil are shown in Table-3. The leaf essential oil of T. meifolious reduced the concentration of DPPH free radical $(55.6 \pm 1.5 \%, 10 \mathrm{mg} /$ $\mathrm{mL}$ of essential oil), with an efficacy lower than that of reference oil T. X-porlock (69.3\% inhibition). $\mathrm{IC}_{50}$ for $\mathrm{DPPH}$ radical-scavenging activity was $3.75 \mu \mathrm{g} / \mathrm{mL}$.

$\boldsymbol{\beta}$-Carotene-linoleic acid assay: The lipid peroxidation inhibitory activities of the essential oil was assessed by the $\beta$-carotene bleaching test. Results of the reference oil (T. $X$ porlock) were almost consistent with data obtained from the DPPH test. In $\beta$-carotene-linoleic acid test system, oxidation of linoleic acid was effectively inhibited by $T$. meifolious oil $(40.65 \pm 2.5,0.625 \mathrm{mg} / \mathrm{mL}$ of essential oil).

\section{ACKNOWLEDGEMENTS}

The authors thank Department of Biology, Shahed University, Iran for assistance in methodology. The authors are also grateful to Dr.V. Mozaffarian (Research Institute of Forests and Rangelands, Tehran) for helpful assistance in botanical identification.

\section{REFERENCES}

1. K.H. Rechinger, In eds.: K.H. Rechinger and I.C. Hedge, Thecocarpus, In: Flora Iranica, Umbelliferae, No. 162., Akademische Druck and Verlagsansalt, Gras, Austria (1987).

2. V.A. Mozaffarian, Dictionary of Iranian Plant Names, Farhang Moaser, Tehran, Iran (1996).

3. M. Taherkhani, S. Masoudi and A. Rustaiyan, Asian J. Chem., 24, 1596 (2012).

4. R.P. Adams, Identification of Essential Oil Components by Gas Chromatography/Quadrupole Mass Spectroscopy. Allured Publ. Corp., Carol Stream, IL (2001).

5. I. Rasooli and S.A. Mirmostafa, J. Agric. Food Chem., 51, 2200 (2003).

6. T.Y. Lim, Y.Y. Lim and C.M. Yule, Food Chem., 114, 594 (2009).

7. $\quad$ M. Burits, Phytother Res., 14, 323 (2000).

8. M. Cuendet, K. Hostettmann and O. Potterat, Helv Chim. Acta, 80, 1144 (1997).

9. M.S. Taga, E.E. Miller and D.E. Pratt, J. Am. Oil Chem. Soc., 61, 928 (1984).

10. H.S. Choi, H.S. Song, H. Ukeda and M. Sawamura, J. Agric. Food Chem., 48, 4156 (2000). 